\title{
A CONSTITUIÇÃO DO SUJEITO FEMININO EM DOM CASMURRO, LOLITAE LA NADA COTIDIANA
}

http://dx.doi.org/10.11606/issn.2237-1184.v0i23p90-103

Felipe dos Santos Matias

Universidade Federal da Integração Latino-Americana

RESUMO

O presente artigo realiza uma análise acerca da representação do sujeito feminino nos romances Dom Casmurro (1899), de Machado de Assis, Lolita (1955), de Vladimir Nabokov, e La nada cotidiana (1995), de Zoé Valdés, com o intuito de detectar as práticas discursivas e socioculturais que os respectivos narradores veiculam, principalmente em relação ao gênero.

\section{ABSTRACT}

The present article analysis the representation of female subject in the novels Dom Casmurro (1899), by Machado de Assis, Lolita (1955), by Vladimir Nabokov, and La nada cotidiana (1995), by Zoé Valdés, with the aim of detecting the discursive and sociocultural practices that the respective narrators makes, mainly in relation to the gender.
PALAVRAS-CHAVE:

\section{Sujeito.}

Feminino.

Dom Casmurro.

Capitu.

Lolita.

La nada cotidiana.

Yocandra.

\section{KEYWORDS:}

Female.

Subject.

Dom Casmurro.

Capitu.

Lolita.

La nada cotidiana.

Yocandra. 


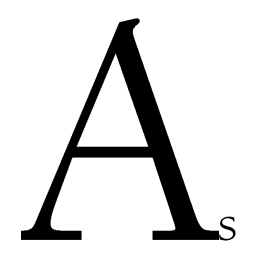

décadas de setenta e oitenta do século XX viram surgir um conjunto de estudos feministas que produziram uma considerável "reavaliação das explicações correntes da vida social, apoiadas na experiência de mulheres e na crítica às teorias sociais, geralmente omissas quanto à importância das relações de gênero na explicação da organização social”" . Os essencialismos propagados pela doxa patriarcal começaram a ser questionados e desconstruídos, visto que justificavam, até então, "arbitrárias divisões, a começar pela divisão socialmente construída entre os sexos, como naturais, evidentes" 2 .

Joan Scott expressa que o termo "gênero" é utilizado "para designar as relações sociais entre os sexos. Seu uso rejeita explicitamente explicações biológicas" ". A partir das ideias dessa estudiosa, pode-se dizer que o gênero é uma forma primária de dar significado às relações de poder, e é também um sistema social, cultural e literário, que é construído a partir de atitudes e valores, por meio dos quais se caracteriza o homem na categoria do masculino e a mulher na do feminino. Segundo Scott, o termo "gênero" faz parte da "tentativa empreendida pelas feministas contemporâneas de reivindicar certo terreno de definição, para sublinhar a incapacidade das teorias existentes para explicar as persistentes desigualdades entre as mulheres e os homens"4 . Para ela, este termo auxiliou na mudança de um paradigma científico para um literário, proporcionando a realização de estudos de constituição de sujeito nas obras literárias.

O conceito de gênero definido por Scott permite refletir sobre todos os aspectos da vida, incluindo sexualidade, identidade, política e divisão do trabalho. Em direção semelhante à dela, Bila Sorj define gênero como sendo "um produto social, aprendido, representado, institucionalizado e

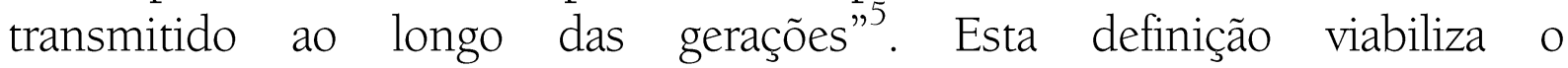
reconhecimento das relações de poder entre homens e mulheres e o estudo

\footnotetext{
${ }^{1}$ SORJ, Bila. O feminismo na encruzilhada da modernidade e pós-modernidade. In: BRUSCHINI, C; COSTA, A. O. (Orgs). Uma questão de gênero. Rio de Janeiro: Rosa dos Tempos, 1992, p. 15.

${ }^{2}$ BORDIEU, Pierre. A dominação masculina. Trad. Maria Helena Kühner. Rio de Janeiro: Bertrand Brasil, 1999, p. 17.

3 SCOTT, Joan. "Gênero: uma categoria útil de análise histórica". Revista Educação \& Realidade, v. 20, n. 2, jul./dez. 1995, p. 75 .

${ }^{4}$ SCOTT, op. cit., p. 85.

${ }^{5}$ SORJ, op. cit., p. 15.
} 
de como essas ações ocorrem, por exemplo, na literatura. Pelo fato de o poder ser distribuído entre os sexos, cabe às mulheres, de acordo Sorj, uma posição subalterna na organização da vida social machista e patriarcal.

Segundo Jane Flax, "o mais importante avanço isolado na teoria feminista consiste em se ter problematizado a existência de relações de gênero" . Para Flax, vivemos num mundo em que o gênero é uma relação social constituinte e também uma relação de dominação. A existência de relações de gênero nos ajuda a ordenar e entender os fatos da existência humana, as relações simbólicas que vigoram na sociedade como um todo e que tendem sempre a justificar a dominação masculina, conforme aponta Pierre Bourdieu:

A ordem social funciona como uma imensa máquina simbólica que tende a ratificar a dominação masculina sobre a qual se alicerça: é a divisão social do trabalho, distribuição bastante estrita das atividades atribuídas a cada um dos dois sexos, de seu local, seu momento, seus instrumentos; é a estrutura do espaço, opondo o lugar de assembleia ou de mercado, reservado aos homens, e a casa, reservada às mulheres; ou, no interior desta, entre a parte masculina, com o salão, e a parte feminina, com o estábulo, a água e os vegetais; é a estrutura do tempo, a jornada, o ano agrário, ou o ciclo de vida, com momentos de ruptura, masculinos, e longos períodos de gestação, femininos ${ }^{\top}$.

De acordo com Lúcia Osana Zolin, "no âmbito da Literatura e da Crítica Literária, a mulher vem figurando entre os temas abordados em encontros, simpósios e congressos, bem como se constituindo em motivo de

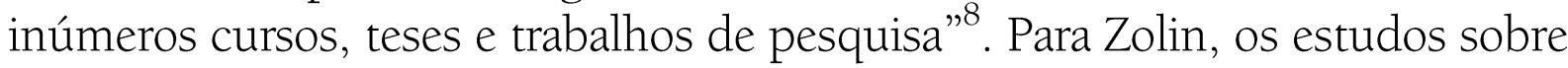
obras literárias canônicas evidenciam sólidas relações entre sexo e poder, visto que as relações entre casais espelham as relações de poder na sociedade patriarcal, na qual o homem se sobrepõe à figura da mulher e a representa de acordo com a visão da ordem social falocêntrica.

A arte literária permite perceber os diferentes modos de enunciação relacionados às mulheres, bem como as diferenças entre os processos de singularização, explicitando, portanto, as tensões e os conflitos entre estes processos, que vão sendo construídos com base na categoria gênero.

\footnotetext{
${ }^{6}$ FLAX, Jane. Pós-modernismo e relações de gênero na teoria feminista. In: HOLANDA, Heloísa Buarque de (Org). Pósmodernismo e política. Rio de Janeiro: Rocco, 1991, p. 226.

${ }_{8}^{7}$ BOURDIEU, op. cit., p. 18.

${ }^{8}$ ZOLIN, Lúcia Osana. Crítica Feminista. In: Teoria Literária: Abordagens Históricas e Tendências Contemporâneas. Maringá: Eduem, 2009, p. 217.
} 
A observação de práticas discursivas em determinadas obras ficcionais possibilita analisar a constituição dos sujeitos feminino e masculino. Ainda permite não só a oportunidade de identificar, mas também de refletir criticamente sobre essa construção e problematizar aqueles significados atribuídos ao gênero que determinam ou favorecem determinadas formas de ser.

O estudo aqui proposto focaliza as representações do sujeito feminino desenvolvidas pelos narradores dos romances Dom Casmurro (1899), de Machado de Assis, Lolita (1995), de Vladimir Nabokov, e La nada cotidiana (1995), de Zoé Valdés, partindo das considerações teóricas sobre gênero expressas anteriormente e do pressuposto de que a linguagem atribui sentido ao mundo e que, dessa forma, constrói a realidade na qual vivemos e nos inserimos. Nesse contexto, os elementos da vida social são conformados discursiva e linguisticamente na forma literária. A linguagem não só expressa as características dos elementos de sentido, mas também os constitui.

Segundo Michel Foucault, todo uso da linguagem se "enraíza numa vida, numa sociedade, numa história". Essa noção foucaultiana permite observar que os discursos não são transparentes, mas sim arbitrários e tendenciosos, veículos de uma determinada ideologia. Desta maneira, podese dizer que a constituição de gênero é realizada nas narrativas literárias como um processo performativo, fundamentalmente atrelado à linguagem, visto que as artimanhas expositivas do narrador são estratégias de persuasão.

Para Mikhail Bakhtin, o sujeito que elabora um discurso é sempre, em certo grau, "um ideólogo e suas palavras são sempre um ideologema, visto que sua linguagem particular representa sempre um ponto de vista sobre o mundo, no qual o sujeito aspira uma significação social" ${ }^{\text {10 }}$. Partindo desse pressuposto teórico bakhtiniano, ressalta-se neste estudo a importância de se perceber que tanto em Dom Casmurro quanto em Lolita os narradores são homens e fazem representações a respeito de suas respectivas mulheres amadas, e estas são constituídas por meio da linguagem, que implica um conhecimento parcial e deve ser percebida como social e historicamente localizada, produto de uma construção discursiva que visa persuadir os possíveis leitores dos respectivos textos. Diferentemente dessas obras que são narradas por sujeitos masculinos e que possuem uma versão depreciativa em

\footnotetext{
${ }^{9}$ FOUCAUlT, Michel. As palavras e as coisas. Trad. Salma Tannus Muchail. São Paulo: Martins Fontes, 1995, p. 390.

${ }^{10}$ BAKHTIN, Mikhail. Questões de literatura e de estética: a teoria do romance. Trad. Aurora Fornoni Bernardini et al. São Paulo: Unesp-Hucitec, 1993, p. 135.
} 
relação ao sujeito feminino, em La nada cotidiana é uma mulher que detém o poder da representação linguística, que representa a si própria e aos sujeitos masculinos com os quais convive ao longo da trama, pois Patria/Yocandra é a narradora-protagonista da obra. Deste modo, objetiva-se aqui confrontar as representações narrativas da escrita feminina (La nada cotidiana) com as das escritas masculinas (Dom Casmurro e Lolita), tendo como base o conceito de gênero.

Nos romances Dom Casmurro (1899), de Machado de Assis, e Lolita (1955), de Vladimir Nabokov, as personagens femininas Capitu e Lolita são vozes silenciadas, pois a representação delas é feita pelos narradorespersonagens, os quais veiculam aquilo que desejam. Desse modo, a constituição do sujeito feminino em ambas as obras passa pelo crivo de representantes da sociedade patriarcal falocêntrica, que configuram suas respectivas amadas com as características que julgam pertinentes, transmitindo ao leitor os valores sociais das sociedades na qual estão inseridos, a brasileira do fim do século XIX, no caso de Bento Santiago, e a norte-americana da década de 50, no caso de Humbert.

Diferentemente de Dom Casmurro e Lolita, na obra La nada cotidiana (1995), de Zoé Valdés, a personagem feminina Patria/Yocandra é quem narra a sua história, veiculando ao longo da narrativa as suas memórias, impressões e angústias relacionadas à sua vida. Nessa obra, é Yocandra quem constitui os sujeitos masculinos, principalmente os seus dois amantes, os personagens Traidor e Nihilista. A respeito de La nada cotidiana, Miguel Angel GonzálezAbellás faz o seguinte comentário:

La nada cotidiana cuenta la historia de Patria, una mujer así llamada por nacer durante el año del triunfo de la Revolución, y con el paso de los años y los desencantos en Cuba, se cambia el nombre por el de Yocandra y se dedica a reflexionar y a escribir sobre la nada que observa a diario en la isla y su amor por dos hombres, el Traidor y el Nihilista ${ }^{11}$.

Tanto em Dom Casmurro e Lolita quanto em La nada cotidiana a narrativa é em primeira pessoa, visto que o(a) narrador(a) também é protagonista. Se, por um lado, a narrativa em primeira pessoa confere verossimilhança ao relato, supondo-se que o narrador ao assumir-se como sujeito do enunciado seja a testemunha mais idônea para contar sua própria

\footnotetext{
${ }^{11}$ GONZÁLEZ-ABELLÁS, Miguel Angel. Aquella isla: introducción al universo narrativo de Zoé Valdés. Hispania, v. 83, n. 1, mar. 2000, p. 44
} 
história, por outro são igualmente conhecidas as artimanhas desse procedimento retórico, dado o comportamento arbitrário dele, que conta o que bem entende e da maneira que julga conveniente, inserindo em seu relato, conscientemente ou não, suas ideologias, crenças e possíveis preconceitos socioculturais. Este tipo de narrador, autodiegético, dá margens a ambiguidades, provoca hesitações, cria um universo de múltiplas possibilidades, por mais que tente construir um discurso homogêneo e centralizante.

Nas narrações de Bento Santiago (marido ciumento, cismado e com perceptíveis perturbações psicológicas) e Humbert (pedófilo e assassino) a reconstituição do passado funciona como estratégia de defesa, pois ao evocarem a Capitu menina e a ninfeta Lolita, respectivamente, cada um deles prepara a sua própria defesa, visto que transferem para as amadas a culpa de seus atos, tentando fazer o leitor crer que foram elas que os seduziram e os conquistaram. Já na narração de Yocandra, a evocação de suas memórias possui um caráter de exposição analítica em relação à sua vida pessoal. Podese dizer que nesse caso também há em certo sentido uma estratégia de defesa, principalmente em relação à vida amorosa, visto que a narradora justifica sua falta de sentimentalidade na relação com os homens em virtude do trauma psicológico que sofreu quando se relacionou e casou com o personagem Traidor, um homem egocêntrico, frio e infiel.

Com isso, nota-se que o papel do narrador é de vital importância nas três obras aqui analisadas, pois é através de cada um deles que vamos conhecer as respectivas histórias, fazer julgamentos e reflexões. Entretanto, deve-se ter em mente que eles também são protagonistas, que querem persuadir os seus leitores (principalmente nas narrativas de Dom Casmurro e Lolita) a respeito das suas versões dos fatos, fazendo uso de suas posições sociais e de suas refinadas educações. Para tal efeito, eles se mostram gentis e atenciosos com o leitor, demonstram um grau diferenciado de erudição. Concordando com John Gledson, pode-se dizer que "o narrador, que também é protagonista, é um enganador que está tentando nos persuadir de uma dada versão dos fatos de sua história"12.

A partir da perspectiva de Gérard Genette, "todo discurso, além de ser emitido por alguém, sempre irá se dirigir a alguém" "13, ou seja, além do discurso ser produzido por determinado alguém, ele possui um destinatário

\footnotetext{
${ }^{12}$ GLEDSON, John. Machado de Assis: impostura e realismo - uma reinterpretação de Dom Casmurro. São Paulo: Companhia das Letras, 1991, p. 95.

${ }^{13}$ GENETTE, Gérard. Discurso da narrativa. Lisboa: Vega, 1995, p. 46.
} 
alvo. Genette afirma que "dessa forma, a instância narrativa não é sustentada unicamente pela participação ficcional do emissor, uma vez que o receptor do texto aí se inscreve ao atuar como intérprete" ${ }^{" 14}$. Essas considerações de Genette nos permitem afirmar que o discurso do narrador é configurado para o leitor, o qual passa a receber toda a carga sócio-ideológica do emissor.

Nas narrativas de Bento Santiago e Humbert o leitor é explicitamente convocado a participar do processo discursivo na condição de intérprete, completando lacunas, tirando conclusões e fazendo julgamentos do que lhe é relatado. Para tanto, os narradores apelam à empatia do interlocutor. Ambos são educados e atenciosos com o leitor, pois há a intenção de persuadi-lo acerca da representação que fazem dos sujeitos femininos. Abaixo, são destacados dois exemplos que evidenciam a atenção e a gentileza dos narradores de Dom Casmurro e Lolita com o leitor:

A leitora, que é minha amiga e abriu este livro com o fim de descansar da cavatina de ontem para a valsa de hoje, quer fechá-lo às pressas, ao ver que beiramos um abismo. Não faça isso, querida; eu mudo de rumo ${ }^{15}$.

Por obséquio, leitor: apesar de sua exasperação com o termo, morbidamente sensível e infinitamente circunspecto herói de meu livro, não pule essas páginas essenciais! Faça um esforço para imaginar-me, pois não existirei se o distinto leitor não for capaz de imaginar-me; tente discernir a corça que havia em mim, tremendo na floresta de minha própria iniquidade; tratemos até de sorrir um pouquinho. Afinal de contas, um sorriso não faz mal a ninguém ${ }^{16}$.

Em La nada cotidiana não existe uma interpelação explícita do leitor, pois a narradora Yocandra não o cita nominalmente. Há, entretanto, uma convocação implícita, pois ela se preocupa em explicar e detalhar algumas situações de sua vida, principalmente em relação ao envolvimento passional com a personagem o Traidor, conforme ilustra o fragmento a seguir:

¿Cómo conocí al Traidor? Yo regresaba de las clases de mecanografía que recibía de una mulatona que pretendía ser refinada, sofisticada y de salón, y que tenía su escuela clandestina en un solar del Callejón de Chorro [...] Él me persiguió, no pudo resistir la tentación, me le antojé candorosa, empapadita, el agua transparentaba mi vestido y sus dientes hubieran querido volar para marcar mi dura carne, mi "señora piel", como el poema de Lezama dedicado a Fina. (El Traidor me contaría años

\footnotetext{
${ }^{14}$ Idem, ibidem, p. 47.

${ }_{10}^{15}$ ASSIS, Machado de. Dom Casmurro. São Paulo: Klick Editora, 1997, p. 132.

${ }^{16}$ NABOKOV, Vladimir. Lolita. Trad. Jorio Dauster. Rio de Janeiro: O Globo, 2003, p. 131.
} 
después que Lezama estuvo toda su vida enamorado de ella, platónicamente,

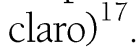

Nota-se no fragmento acima que a narradora Yocandra dá indícios de um diálogo implícito com o leitor, visto que responde a uma possível questão de interesse dele, explicando alguns detalhes acerca de como conheceu o Traidor, e faz um parêntese para dar uma explicação extra. Assim como Bento Santiago e Humbert, Yocandra também apela à empatia do interlocutor, convocando-o a participar de sua narrativa, mesmo que implicitamente.

De acordo com Flávio Kothe, em Dom Casmurro o narrador Bento Santiago propaga os valores e preconceitos sociais que a sua sociedade tinha contra a mulher, ou seja, ele "quer a mulher guardada em casa, sem trabalhar

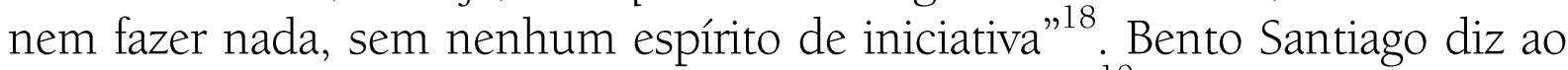
leitor que "as mulheres sejam sujeitas a seus maridos"19. Do mesmo modo, o narrador Humbert também tenta manter a sua jovem amada, Lolita, reclusa em casa, submissa, sem participar de atividades artísticas e sociais como a encenação de uma peça teatral, dificultando a convivência dela com jovens da mesma idade, configurando-se, assim como Bento Santiago, em um patriarca repressor que não aceita a liberdade da mulher:

Para começar, o velho bicho-papão fez uma lista do que era "absolutamente proibido" e outra do que era "relutantemente proibido". [...] Ela podia ir a uma confeitaria com os colegas e lá conversar ocasionalmente, ou até mesmo dar umas risadinhas $[. .$.$] deixei totalmente claro que, enquanto durasse meu regime, nunca,$ mas nunca mesmo, lhe seria permitido ir ao cinema ${ }^{20}$.

Na obra de Zoé Valdés, Yocandra denuncia os preconceitos sociais que a sociedade falocêntrica tinha (e ainda hoje tem em muitos casos) contra o gênero feminino, a qual dissemina que a mulher não tem a liberdade de contestar o marido e de trabalhar se for casada, pois deve cuidar da casa, preparar a comida do esposo, lavar sua roupa, satisfazer os seus desejos sexuais, fazer vista grossa e/ou perdoar suas traições, etc. O excerto a seguir é um exemplo disso:

Aún es mi marido, porque debo señalar que, antes de salir en las mañanas, cuando ya estoy lista en la puerta, bañada, vestida con mi ropa limpia y planchada, el abrigo

\footnotetext{
${ }^{17}$ VALDÉS, Zoé. La nada cotidiana. Buenos Aires: Emecé Editores, 1995, p. 39-40.

${ }^{18}$ KOTHE, Flávio. Fundamentos da teoria literária. Brasília: Editora da Universidade de Brasília, 2002, p. 399.

${ }^{19}$ ASSIS, op. cit., p. 183

${ }^{20}$ NABOKOV, op. cit., 188
} 
impecablemente sacudido, sin una basurita, peinada, perfumada, entonces es cuando a él se le antoja singarme con ropa y todo encima de la colcha blanca que suelta pelusitas, o de la alfombra polvorienta, porque él no se gastará un quilo en comprar el espray limpialfombras, ni yo tampoco claro está. (Como esposa acompañante sólo gano sesenta dólares al mes y no tengo derecho a trabajar fuera). A esa hora debo volver a quitarme la ropa, bañarme nuevamente, introducirme un óvulo de nistatina en la vagina porque parece que él ha tenido relaciones con una venezolana de la UNESCO que le ha pegado una trichomona del carajo. Ten paciencia y perfúmate de nuevo, repíntate los labios. Y cuando parece que puedes salir a batirte con las oleadas gélidas de la mañana, él te procura, dulce, casi tierno, e indefenso:

- Amor, ¿dejaste mi comida preparada? ${ }^{21}$

Há do ponto de vista narrativo uma grande semelhança entre Capitu e Lolita: a quase total exclusão de suas vozes como narradoras, visto que a fala de ambas é suprimida ou deformada pela perspectiva unívoca do narrador masculino, o qual é o detentor da palavra, do discurso. Em oposição, a voz de Yocandra possui a liberdade de expressão, com a consequente denúncia e combate à dominação machista, conforme se observa no excerto anterior. $\mathrm{Na}$ narrativa de Zoé Valdés, a personagem feminina toma o poder da palavra, representa incisivamente os mandos e desmandos dos sujeitos masculinos, aponta-os como responsáveis pela repressão e danos psicológicos causados às mulheres. Como exemplo de denúncia destes danos, pode-se citar o trecho em que Yocandra relembra a perda forçada da virgindade na adolescência/juventude, visto que o homem pelo qual estava apaixonada, o Traidor, não queria fazer sexo com uma virgem. Ela, então, é praticamente obrigada a se relacionar sexualmente com um desconhecido para, somente assim, poder viver uma relação com o seu amado:

La segunda vez me preguntó si yo era virgen. Claro que respondí sí, realmente lo era, nadie aún había penetrado mi vulva, mi himen estaba intacto. Él no podía admitir aquello. Me amenazó con el dedo y me partió para arriba visiblemente airado. Si yo era virgen alguien tenía que desvirgarme, pero jamás él. Él era incapaz, no soportaba a las vírgenes, él no se atrevía a romper algo tan delicado y húmedo, iel himen! (¿Cómo iba a sospechar que mucho tiempo después, y muy a menudo, iba a desgarrar zonas más sensibles en mí: la dignidad, el alma, y toda esa mojonería tan importante para nosotras? $)^{22}$

[...]

\footnotetext{
${ }^{21}$ VALDÉS, op. cit., p. 63-64.
}

${ }^{22}$ VALDÉS, op. cit., p. 41-42. 
Regresé al cuartucho del Traidor. Por supuesto, él no me esperaba. Abrió somnoliento - ya era madrugada - y bostezó sin cuidarse de no mostrarme los empastes. Yo lo aparte a un lado y entré ligera. Como a punto de bailar un vals.

- Ya-dije sonriente, en el colmo del éxtasis.

-¿Ya qué? - preguntó al tiempo que encendía un cigarrillo.

- Ya me partieron.

- Quieres decir que ya no eres...

- Eso... virgen... Con permiso, ipuedo lavarme? - La esperma del melenudo me corría por las rodillas ${ }^{23}$.

O relato memorialístico de Yocandra é ao mesmo tempo chocante e sensibilizador, pois é a voz de uma mulher experiente e sofrida, que relembra a perda de sua inocência, ocorrida em função de uma idealização amorosa. No entanto, essa perda e os subsequentes danos psicológicos não passam impunes do ponto de vista da linguagem, devido ao fato de que Yocandra faz uso de sua voz narrativa para delatar o homem que tanto mal fez a ela, que se aproveitou de sua ingenuidade, de sua paixão adolescente:

El Traidor desvirgó mi inocencia si hoy soy despiadada es por su culpa. Era el destinado a violar mis sueños y lo hizo cruelmente. Era el que debía mentirme y me mató a mentiras. Era el que marca, y aquí estoy cubierta de cicatrices. [...] Yo lo amé como sólo puede hacerlo una adolescente $e^{24}$.

Distintamente de Yocandra, as vozes de Capitu e Lolita somente conseguem manifestar-se por meio do e no interdito, pelas pequenas brechas do discurso patriarcal do repressor, e é nessas mínimas aberturas que se podem perceber caminhos para a refutação e a desconstrução do que é narrado, que se pode observar a angústia sofrida pelo sujeito feminino:

- Não Bentinho, ou conte o resto, para que eu me defenda, se você acha que tenho defesa, ou peço-lhe desde já a nossa separação: não posso mais! [...] Pois até os defuntos! Nem os mortos escapam aos seus ciúmes! $!^{25}$

- Seu bruto! [...] Você não vale nada. Eu era uma mocinha pura e inocente, e olha só o que você fez comigo. Devia chamar a polícia e dizer que você me violentou. Ah, seu velho sujo, sujo! ${ }^{26}$

\footnotetext{
${ }^{23}$ VALDÉS, op. cit., p. 44-45.

${ }^{24}$ VALDÉS, op. cit., p. 45.

${ }^{25}$ ASSIS, op. cit., p. 237.

${ }^{26}$ NABOKOV, op. cit., p. 142-143.
} 
Nos dois excertos, percebe-se o desespero dos dois sujeitos femininos com relação aos seus parceiros. No caso de Capitu, esse é um dos raros momentos dentro da narrativa que ela pode se defender das constantes acusações de Bento Santiago, chegando ao ponto de pedir a separação por não aguentar mais a pressão e refreamento que sofre do ciumento companheiro. Com relação à Lolita, ela expressa toda a indignação e asco que sente por Humbert, que a explora sexualmente sem o menor escrúpulo e pudor. Assim, depreende-se que tanto em Dom Casmurro quanto em Lolita a voz do sujeito feminino consegue permear o discurso do narrador, atormentando-o nas reminiscências, criando fantasmagorias de sombras à beira e por dentro da narrativa.

Capitu, quando menina, e Lolita são apresentadas como jovens fascinantes, encantadoras e sedutoras para demonstrar melhor a "armadilha" que representam, a "desgraça" que preparam contra as pretensas "vítimas" masculinas com quem convivem. Por meio desta atitude, os narradores identificam as respectivas amadas como femmes fatales, aproximando-as de Lilith - símbolo da mulher atraente e volúvel que usa os poderes de sedução para atormentar a vida dos homens que por ela se apaixonam. São expostos a seguir dois fragmentos para ilustrar o que foi dito:

Se isto vos parece enfático, desgraçado leitor, é que nunca penteastes uma pequena, nunca pusestes as mãos adolescentes na jovem cabeça de uma ninfa... Uma ninfa! [...] Ainda há pouco, falando dos olhos de ressaca, cheguei a escrever Tétis [...] palavra que envolve todas as potências cristãs e pagãs ${ }^{27}$.

Lentamente sua cabeça se voltou para o outro lado e tombou sobre os travesseiros de que ela se havia injustamente apropriado. Fiquei imóvel na minha beirada, olhando seus cabelos em desalinho, o brilho de sua pele de ninfeta (meio quadril $e$ meio ombro entrevistos vagamente) ${ }^{28}$.

No caso de Lolita, desde sua criação em 1955, a personagem título da obra de Vladmir Nabokov vem povoando o imaginário dos leitores ao combinar sedução feminina e ingenuidade infantil, apesar da necessidade de se levar em consideração que ela é uma construção discursiva do narrador, pois esta caracterização só existe em função de sua pedofilia, conforme se evidencia no excerto abaixo:

\footnotetext{
${ }^{27}$ ASSIS, op. cit., p. 73.

${ }^{28}$ NABOKOV, op. cit., p. 131
} 
Eu estava de pé, as costas voltadas para a porta, e de repente senti que o sangue me subia à cabeça aos borbotões quando ouvi sua respiração e sua voz atrás de mim. Ela chegou arrastando e batendo sua pesada mala. "Oi!", ela disse, e ficou parada, olhando-me com um olhar ao mesmo tempo furtivo e alegre, os lábios macios e entreabertos num sorriso algo tolo mas maravilhosamente encantador ${ }^{29}$.

Lolita é descrita fisicamente pelo narrador Humbert como uma bela ninfeta, uma "ginasiana pubescente", uma sedutora igual à Carmen, evocando a astuta e encantadora cigana da obra homônima de Prósper Mérimée, a qual também é considerada uma das representações de Lilith. Segundo Woodward, "a identidade é relacional, e a diferença estabelece-se por uma marcação simbólica relativa a outras identidades"30. Desta forma, pode-se pensar que a "ninfeta" só existe em função do olhar deturpado de Humbert, visto que é ele quem constrói essa identidade negativa de Lolita, atribuindo aos hipotéticos encantos e sedução dela a sua desgraça e perdição.

Para o narrador de Dom Casmurro, o essencial é provar que o conhecimento que tinha dos atos de Capitu quando menina lhe possibilitava um julgamento seguro sobre a mulher adulta, que ele qualifica como misteriosa. O seguinte trecho é um exemplo disso: "Mas creio que não, e tu concordarás comigo; se te lembras bem da Capitu menina hás de reconhecer que uma estava dentro da outra, como a fruta dentro da casca"31. Entretanto, a única lembrança que pode ter o leitor da jovem Capitu é a que lhe foi dada pela escrita do narrador, limitando, assim, a confiabilidade da história contada.

Bento Santiago utiliza-se da repetição das metáforas "olhos de ressaca" e "olhos de cigana oblíqua e dissimulada" para ressaltar a ideia do dito popular de que "os olhos são o espelho da alma", e assim tentar convencer o leitor que a Capitu menina já possuía má índole, pois seus olhos, caracterizados de modo traiçoeiros como o mar, atraem para destruir, qualificando-a negativamente: "Capitu, apesar daqueles olhos que o diabo lhe deu... Você já reparou nos olhos dela? São assim de cigana oblíqua e dissimulada" 32 .

O fato de o narrador de Dom Casmurro ser um aristocrata e um cidadão acima de qualquer suspeita - o bacharel com bela cultura, o filho carinhoso, o marido cioso, o proprietário abastado, o moço com educação

\footnotetext{
${ }^{29}$ NABOKOV, op. cit., p. 112

${ }^{30}$ WOODWARD, Kathryn. Identidade e diferença: uma introdução teórica e conceitual. In: SILVA, Tomaz Tadeu da (Org). Identidade \& Diferença. Petrópolis: Vozes, 2000, p. 14.

${ }^{31}$ ASSIS, op. cit., p. 152.

32 ASSIS, op. cit., p. 57.
} 
católica, o cavalheiro da belle époque - o torna merecedor de todo apreço e respeito, o que contribui muito para a possível persuasão do interlocutor. A narrativa de Bento Santiago é composta com muita astúcia, com o intuito de iludir, enganar e confundir o leitor o tempo todo.

Em La nada cotidiana, a personagem masculina Traidor também tenta jogar a culpa do seu fracasso pessoal e artístico em cima da companheira Yocandra, mas por ela deter o poder da linguagem e representação, desmascara todo o machismo, covardia e incompetência intelectual do companheiro. A narradora-protagonista divorcia-se dele, libertando-se simbolicamente das algemas da sociedade patriarcal:

Regresé y una vez más fui sincera. Confesé que había descubierto su novela y que la había leído.

- ¿Genial, no? - fue su respuesta socrática, es decir, por el hecho de haber contestado con una pregunta.

Mientras yo hacía las maletas, él amenazaba con el suicidio. Fui a la cocina y sin el más mínimo comentario ni asomo de alarma le puse el cuchillo en las manos. Siguió lamentándose. Fui al botiquín y le preparé al cianuro. Continuó gimoteando. Lo penúltimo que escuché fue:

- Por culpa tuya no puedo escribir. Siento que me espías y eso me inhibe. Todos me espían, pero tú con más encono... Tú eres la culpable...

Por un tin así no solté la carcajada ${ }^{33}$.

No fragmento acima, nota-se por parte do Traidor a mesma postura covarde de Bento Santiago e de Humbert, a de colocar a culpa na companheira por suas atitudes e debilidades. No entanto, na obra de Valdés é o sujeito feminino que elabora o discurso narrativo, e desta forma o sujeito masculino é constituído com todas as suas hipocrisias e ridículos. Yocandra desnuda em sua narrativa a fraqueza e incapacidade do companheiro, expressando a sua vontade de dar uma gargalhada ao ouvir as lamúrias infundadas dele. $O$ absurdo das ações do ex-companheiro pode ser observado na atitude melodramática de pedir que Yocandra o mate, no momento em que ela começa a arrumar as malas para se divorciar dele:

El Traidor vino corriendo, me puso la hoja afilada entre las manos, abrió la camisa de su pijama color punzó, y arrodillado suplicó:

- iMátame, mátame! iAsesíname!

Ni hablar, pensé yo. Imaginé los titulares en los diarios y en el noticiero: "Talentoso escritor cubano muere descuartizado a manos de su esposa joven e aburrida, una

${ }^{33}$ VALDÉS, op. cit., p. 65. 
inútil que lo único que hacía era vagabundear mientras él sudaba y se desvivía trabajando en las páginas de su última y genial novela". Recogí mis pertenencias como pude, a lo loco, dejando sin duda cosas de valor y llevándome las boberías que el nerviosismo me permitía ver, en medio de aquel capítulo digno del más vil culebrón venezolano.

Pensé que sería fácil para él olvidarme. En cierta ocasión, almorzando en un restorán habanero con nombre francés, La Fayette, me había dicho que para él no constituía ningún trauma borrar a una mujer de su mapa. Sólo tenía que pensar y fijar sus defectos físicos, y con ese método ya la exterminaba. Yo tengo varios, por desgracia. O por suerte $e^{34}$.

Yocandra representa com ironia e bom humor a covardia e o caráter melodramático do companheiro, mencionando que, por ser mulher, seria execrada e condenada publicamente pelas notícias jornalísticas, caso assassinasse de fato o Traidor, mesmo se estivesse cumprindo apenas a vontade dele, em razão de que a imprensa é, muitas vezes, partidária da ideologia falocentrista.

Após o exposto neste estudo, pode-se dizer que na narrativa literária autodiegética nenhuma constituição de gênero é neutra, pois há sempre uma manipulação do narrador em função de interesses subjacentes à elaboração da escritura/narração. Nessa direção, a presente reflexão buscou desenvolver a ideia de que em Dom Casmurro e Lolita as personagens Bento Santiago e Humbert se constituem como sujeitos de discursos machistas e repressores em relação às mulheres amadas (Capitu e Lolita), visto que estão inseridos em formações socioculturais que se configuram como um campo de domínio masculino. Em contrapartida, a narrativa de La nada cotidiana configura a liberdade de expressão da voz feminina (a de Yocandra), caracterizando-se como um discurso de denúncia e desconstrução em relação às opressões sofridas pelo gênero feminino nas sociedades falocêntricas e patriarcais.

${ }^{34}$ VALDÉS, op. cit., p. 65-66. 